\title{
Editorial
}

\section{Once upon a Time a Guideline Was Used for the Evaluation of Suspected Choledocholithiasis: A Fairy Tale or a Nightmare?}

\author{
Jorge Canena \\ Centro de Gastrenterologia do Hospital Cuf Infante Santo, Nova Medical School - Faculdade de Ciências Médicas \\ da UNL, Lisbon, Serviço de Gastrenterologia do Hospital Amadora-Sintra, Amadora, Serviço de Gastrenterologia do \\ Hospital de Santo António dos Capuchos, CHLC, Lisbon, and CINTESIS - Center for Health Technology and Services \\ Research, Porto, Portugal
}

Keywords

Choledocholithiasis · Guidelines · ERCP

\section{Era Uma Vez Um Guideline sobre o Diagnóstico de Coledocolitíase: Um Conto de Fadas ou Um Pesadelo?}

\section{Palavras Chave \\ CPRE · Coledocolitíase · Guidelines}

A guideline should always be seen as an educational device. Guidelines are prepared by a panel of experts on the field based on a critical review of the quality of available evidence. Guidelines are used to assist endoscopists while providing the standard of care to patients and should not be used as a rule. However, the question remains: are all guidelines useful or equivalent in quality?

Gallstone disease is a common clinical problem. In Europe, ultrasound studies revealed a prevalence of 9-21\% and an incidence of $0.63 / 100$ persons/year [1-4]. Choledocholithiasis or common bile duct (CBD) stones are a frequent complication of gallstone disease and are pres-

\begin{tabular}{|c|c|}
\hline KARGER & (C) 2017 Sociedade Portuguesa de Gastrenterologia \\
\hline 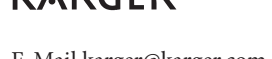 & $\begin{array}{l}\text { Karger } \\
\text { Open access }\end{array}$ \\
\hline www.karger.com/pjg & $\begin{array}{l}\text { This article is licensed under the Creative Commons Attribution- } \\
\text { NonCommercial-NoDerivatives } 4.0 \text { International License (CC BY- } \\
\text { NC-ND) (http://www.karger.com/Services/OpenAccessLicense). } \\
\text { Usage and distribution for commercial purposes as well as any dis- } \\
\text { tribution of modified material requires written permission. }\end{array}$ \\
\hline
\end{tabular}

ent in up to $20 \%$ of the patients $[2,3]$. The approach used in these patients is most important because CBD stones are a common cause of hospitalization due to recurrent symptoms, cholangitis, and pancreatitis [5]. Once the diagnosis of choledocholithiasis is made, stones should be removed by a therapeutic procedure, namely endoscopic retrograde cholangiopancreatography (ERCP), which is the gold standard for the treatment of CBD stones [3-5]. However, although ERCP is highly effective for the extraction of CBD stones, it is associated with a reasonable rate of adverse events, some of them life-threatening [6, 7]. For many clinicians, the initial evaluation of patients with suspected choledocholithiasis includes serum liver biochemical tests (aspartate aminotransferase, alanine aminotransferase, alkaline phosphatase, and total bilirubin) and a transabdominal ultrasonography (US) [8-10] to select patients for other procedures, such as magnetic resonance cholangiopancreatography (MRCP) [11] or endoscopic ultrasound (EUS) [12], before they recommend ERCP to the patient; thus, they are trying to avoid the overuse of ERCP, which should not be a diagnostic procedure because it is associated with complications [6, 7]. In 2010, the American Society for Gastrointestinal Endoscopy (ASGE) published guidelines for the prediction of risk stratification for patients being evaluated for CBD

Prof. Jorge Canena

Centro de Gastrenterologia do Hospital Cuf Infante Santo Nova Medical School - Faculdade de Ciências Médicas da UNL Travessa do Castro 3, PT-1350-070 Lisbon (Portugal) E-Mail jmtcanena@ live.com.pt 
stones [4]. The guideline classifies patients into high risk $(>50 \%)$, intermediate risk (10-50\%), and low risk of choledocholithiasis $(<10 \%)$ as far as the probability of having CBD stones is concerned. Patients at high risk were defined as having any of the very strong predictors of choledocholithiasis (i.e., CBD stones on transabdominal US, clinical ascending cholangitis, or serum bilirubin level $>4$ $\mathrm{mg} / \mathrm{dL}$ ) or both strong predictors (i.e., dilated CBD on US, namely $>6 \mathrm{~mm}$ with gallbladder in situ, and bilirubin level $1.8-4 \mathrm{mg} / \mathrm{dL}$ ). Patients at intermediate risk were those with the presence of 1 strong predictor or any moderate predictor (abnormal liver biochemical tests other than bilirubin, age older than 55 years, and clinical gallstone pancreatitis). Patients with low risk were those with no predictors present. Based on these guidelines, patients at high risk should directly receive ERCP, patients at intermediate risk should be submitted to less invasive evaluations, namely preoperative MRCP or EUS or as an alternative an intraoperative fluorocholangiography (IOFC), and, finally, patients at low risk could directly go on to laparoscopic cholecystectomy without the need for IOFC. However, before further analysis of the literature after the release of these guidelines, the reader should keep in mind the following issues: (a) guidelines are educational devices that may assist endoscopists in taking decisions and not rules; (b) clearly, the ASGE guidelines define patients with $>50 \%$ probability of having a CBD stone as being at high risk; (c) these guidelines were issued with the goal of reducing the overuse of ERCP and, therefore, of increasing patients' safety, and (d) they were issued to minimize the number of unnecessary radiologic procedures, which have been associated with excessive expenditures, and, therefore, guidelines should also be evaluated from a perspective of cost-effectiveness [13].

After the release of the ASGE guidelines, several investigators tried to validate them in the clinical scenario. In one study from the USA, 179 patients with ASGE highrisk probability criteria were retrospectively analyzed, and $99(56.3 \%)$ of these patients had a stone/sludge on subsequent confirmation test; therefore, almost $50 \%$ of these patients were submitted to unnecessary ERCP [14]. The overall accuracy of the guidelines was, in this study, $62.1 \%$ (47.4\% sensitivity and $73 \%$ specificity). In Spain, a prospective study analyzed 256 patients with suspected choledocholithiasis [3]. Of the 208 patients with high-risk probability criteria for CBD stones, 124 (59.6\%) patients were found to have a stone/sludge on ERCP, providing an overall accuracy of 59.0\% (85.5\% sensitivity and $24.3 \%$ specificity). The remaining 48 patients had an intermediate probability of CBD stones, and only $21(43.8 \%)$ had a

Evaluation of Suspected

Choledocholithiasis stone/sludge, providing an accuracy of $41.0 \%$ (14.4\% sensitivity and $75.6 \%$ specificity). Another study prospectively observed 336 patients with suspected choledocholithiasis [15]. Of the 244 patients with a high-risk probability of CBD stones, 185 (75.8\%) were found to have stones on ERCP (accuracy of 69.05\%). Of the 92 patients with an intermediate risk for choledocholithiasis, 45 (48.9\%) had stones on ERCP (accuracy 39.95\%). Another study from the USA retrospectively analyzed 71 patients which met ASGE high-risk probability criteria for CBD stones [16]. Of these, only 39 (54\%) were found to have a stone on ERCP. Overall, in this study, the accuracy of the guidelines was $63 \%$ (sensitivity $54.9 \%$ and specificity 68.6\%). In China, the largest published series included 1,171 patients with high-risk criteria [5]. Of these 1,171 patients, definitive testing (MRCP, EUS, IOFC, and $\mathrm{ERCP})$ revealed CBD stones in 1,076 (40\%) patients $(70 \%$ sensitivity and $74.3 \%$ specificity).

Taken together, the published studies show that the guidelines performed exactly as they were intended to perform. I remember that patients at high risk were defined as having a probability of choledocholithiasis $>50 \%$. Published series reported that patients with high-risk criteria for $\mathrm{CBD}$ stones had a documented stone/sludge in a range between 40 and $79.8 \%$ (average $60.1 \%$ ) of the ERCPs $[2,3,5,14-16]$. The majority of the published series concluded that the ASGE criteria demonstrated a probability of $>50 \%$ of the patients having CBD stones. However, authors should also consider that the ASGE guidelines performed suboptimally, and the application of the current guidelines would lead to unnecessary diagnostic ERCPs in more than one-third of the patients, which is not acceptable $[2,3,5,14-16]$.

One issue that has not been systematically tested is the application of the ASGE guidelines in patients with acute cholecystitis. It is important to remember that the abovementioned guidelines were not developed nor validated for patients with acute cholecystitis. Furthermore, patients with acute cholecystitis have elevated liver enzymes and elevated bilirubin (sometimes $>4 \mathrm{mg} / \mathrm{dL}$ ), which can be conflicting for the diagnosis of CBD stones [17], and abdominal ultrasound can be associated with a poorer detection rate of CBD stones in these patients [18]. In this issue of GE - Portuguese Journal of Gastroenterology, Gouveia et al. [19] retrospectively analyzed 4,369 patients with acute cholecystitis, and only $40(0.92 \%)$ patients had a clinical or a sonographic suspicion of choledocholithiasis, which is not in line with the reported literature, where patients with acute cholecystitis have CBD stones in rates ranging from 9 to $58 \%[17,18]$. As this was a retrospective

GE Port J Gastroenterol 2018;25:6-9 DOI: $10.1159 / 000481688$ 
analysis, we can always raise the question if the patients were correctly encoded for the diagnosis of acute cholecystitis. Further, the low number of patients included limited the strength of the analysis and our conclusions. Nonetheless, 31 patients had ASGE high-probability criteria for CBD stones and 9 had an intermediate risk. Not surprisingly, of the 31 patients with high-risk criteria, only $16(51.6 \%)$ patients were found to have CBD stones, providing an accuracy of $57 \%$, and these values were well in line with the published literature. However, in the study of Gouveia et al. [19], the specificity was $31.8 \%$ and the positive predictive value $52 \%$, which are lower values than those previously published and suggest that in this group of patients (acute cholecystitis) the ASGE guidelines perform even poorer than in the usual clinical scenario. Interestingly, and when using only the liver function tests (LFTs) in patients with acute cholecystitis, we found conflicting results in the literature. In a study from Sweden, when using LFTs as predictors of choledocholithiasis in patients with acute cholecystitis, the authors found a positive predictive value of 9\% [17]. However, in a recent paper from Korea, the authors analyzed patients with acute cholecystitis which were divided into 2 groups (with and without CBD stones) [20]. They analyzed LFT values on initial admission and the changes of LFT values over time after admission. Of all the LFT variables analyzed, $\gamma$-glutamyl transpeptidase was the most reliable variable for predicting the presence of $\mathrm{CBD}$ stones, with a sensitivity of $80.6 \%$ and a specificity of $75.3 \%$ at the cutoff level of $224 \mathrm{IU} / \mathrm{L}$. Finally, the authors concluded that the LFT values on initial admission and the changes in
LFT values over time are reliable predictors of CBD stones in patients with acute cholecystitis.

In conclusion, the ASGE guidelines may lead to an unnecessarily large number of ERCPs, which can be associated with complications. Further, in the scenario of acute cholecystitis, the ASGE guidelines have a low positive predictive value and specificity and, therefore, perform poorer in the above-mentioned group of patients, leading to an excessive overuse of ERCP as described in the paper of Gouveia et al. [19]. It is clear that the ASGE guidelines should be re-opened for discussion. The optimal cost-effectiveness approach for patients with suspected CBD stones is unknown, but new modalities should be used. $\mathrm{He}$ et al. [5] suggest that a revised algorithm with more stringent criteria that includes choledocholithiasis on abdominal US and/or bilirubin levels $>4 \mathrm{mg} / \mathrm{dL}$ plus CBD dilation on abdominal US may improve patient selection and reduce the risk of diagnostic ERCP. However, in the clinical scenario, most of the authors $[3,5,14-16]$, including myself, advocate the use of alternative diagnostic strategies for all patients with high and intermediate probability of choledocholithiasis, namely MRCP or EUS before ERCP. The ASGE guidelines should be used carefully because they are not a fairy tale for sure, and a lifethreatening complication of a diagnostic ERCP is always a nightmare.

\section{Disclosure Statement}

The authors have no conflicts of interest to declare.

\section{References}

1 Cynthia WK, Sum PL: Epidemiology and natural history of common bile duct stones and prediction of disease. Gastrointest Endosc 2002;56(6 suppl):S165-S169.

2 Magalhaes J, Rosa B, Cotter J: Endoscopic retrograde cholangiopancreatography for suspected choledocholithiasis: from guidelines to clinical practice. World J Gastrointest Endosc 2015;7:128-134.

3 Narváez-Rivera RM, González-González JA, Monreal-Robles R, García-Compean D, PazDelgadillo J, Garza-Galindo AA, et al: Accuracy of ASGE criteria for the prediction of choledocholithiasis. Rev Esp Enferm Dig 2016;108:309-314.
4 American Society for Gastrointestinal Endoscopy (ASGE): The role of endoscopy in the evaluation of suspected choledocholithiasis. Gastrointest Endosc 2010;71:1-9.

5 He H, Tan C, Wu J, Dai N, Hu W, Zhang Y, et al: Accuracy of ASGE high-risk criteria in evaluation of patients with suspected common bile duct stones. Gastrointest Endosc 2017;86:525-532.

6 Chandrasekhara M, Khashab MA, Muthusamy VM, Acosta RD, Agrawal D, Bruining $\mathrm{DH}$, et al: Adverse events associated with ERCP - ASGE guideline. Gastrointest Endosc 2017;85:32-47.

7 Canena J, Liberato M, Horta D, Romão C, Coutinho P: Short-term stenting using fully covered self-expandable metal stents for the treatment of refractory biliary leaks, postsphincterotomy bleeding and perforations. Surg Endosc 2013;27:313-324.
8 Barkun AN, Barkun JS, Fried GM, Ghitulescu G, Steinmetz O, Pham C, et al: Useful predictors of bile duct stones in patients undergoing laparoscopic cholecystectomy. Ann Surg 1994;220:32-39.

9 Onken JE, Brazer SR, Eisen GM, Williams DM, Bouras EP, DeLong ER, et al: Predicting the presence of choledocholithiasis in patients with symptomatic cholelithiasis. Am J Gastroenterol 1996;91:762-767.

10 Pedersen OM, Nordgard K, Kvinnsland S: Value of sonography in obstructive jaundice. Limitations of bile duct caliber as an index of obstruction. Scand J Gastroenterol 1987;22: 975-981. 
11 Lee YT, Chan FKL, Leung WK, Chan HL, Wu JC, Yung MY, et al: Comparison of EUS and ERCP in the investigation with suspected biliary obstruction caused by choledocholithiasis: a randomized study. Gastrointest Endosc 2008;67:660-668.

12 Hjartarson JH, Hannesson P, Sverrisson I, Blöndal S, Ívarsson B, Björnsson ES: The value of magnetic resonance cholangiopancreatography for the exclusion of choledocholithiasis. Scand J Gastroenterol 2016;51:1249-1256.

13 Singhvi G, Ampara R, Baum J, Gumaste V: ASGE guidelines result in cost-saving in the management of choledocholithiasis. Ann Gastroenterol 2016;29:85-89.

14 Adams MA, Hosmer AE, Wamsteker EJ, Wamsteker EJ, Andreson MA, Elta GH, et al: Predicting the likelihood of a persistent bile duct stone in patients with suspected choledocholithiasis: accuracy of existing guidelines and the impact of laboratory trends. Gastrointest Endosc 2015;82:88-93.

15 Sethi S, Wang F, Korson AS, Krishnan S, Berzin TM, Chuttani R, et al: Prospective assessment of consensus criteria for evaluation of patients with suspected choledocholithiasis. Dig Endosc 2016;28:75-82.

16 Suarez AL, LaBarre NT, Cotton PB, Payne KM, Coté GA, Elmunzer BJ: An assessment of existing risk stratification guidelines for the evaluation of patients with suspected choledocholithiasis. Surg Endosc 2016;30:4613-4618.

17 Videhult P, Sandblom G, Rudberg C, Rasmussen IC: Are liver function tests, pancreatitis and cholecystitis predictors of common bile duct stones? Results of a prospective, pop- ulation-based cohort study of 1,171 patients undergoing cholecystectomy. HBP (Oxford) 2011;13:519-527.

18 Stott MA, Farrands PA, Guyer PB, Dewbury KC, Browning JJ, Sutton R: Ultrasound of the common bile duct in patients undergoing cholecystectomy. J Clin Ultrasound 1991;19: 73-76.

19 Gouveia C, Loureiro R, Ferreira R, Ferreira A, Santos AA, Santos MP, et al: Performance of choledocholithiasis diagnostic score in patients with acute cholecystitis. GE Port J Gastroenterol, DOI 10.1159/000479973.

20 Ahn KS, Yoon YS, Han HS, Cho JY: Use of liver function tests as first-line diagnostic tools for predicting common bile duct stones in acute cholecystitis patients. World J Surg 2016;40:1925-1931. 